\title{
CORRESPONDENCE
}

\section{Animated video to enhance surgical training during COVID-19 pandemic}

(c) The Author(s), under exclusive licence to The Royal College of Ophthalmologists 2021

Eye (2022) 36:1505-1506; https://doi.org/10.1038/s41433-021-01682-z

\section{TO THE EDITOR:}

We read with interest the paper by Ferarra et al. [1]. Reduction in surgical exposure has in fact affected surgical training both in direct surgical skills acquisition and as well as observational surgical learning. Were herein share an example of our recent innovation using animated video to complement surgical simulation.

Reduction in direct surgical exposure during COVID-19 has reduced the opportunity for direct demonstration of surgical skills in the theatre environment. To overcome this issue, we used SketchUp (Trimble Inc, Boulder, Colorado, USA), an engineering software to create video to simulate a theatre environment. The animation consists of routine cataract theatre staff (surgeon, scrub nurse and floor nurse) whilst demonstrating a scenario in the theatre when posterior capsular rupture (PCR) occurs (Fig. 1).

Peyton's four steps (demonstration, deconstruction, comprehension and performance) is one of the most common methods used in practical skill training $[2,3]$. Using animated video, new knowledge (in this case, PCR) is demonstrated. Following video demonstration, trainees can be asked to deconstruct and perform PCR management using a virtual reality eye simulator and a simulated patient for communication skill practice.

To testify the acceptability of animated video, we have collected feedback from trainees in our deanery. Of the 15 respondents, 93\% of trainees feel strongly agree they would recommend this video to other Ophthalmology residents and all trainees feel the video increased their confidence in PCR management.

An Animated video that simulates the theatre environment is useful to teach management of a rare complication such as PCR. It is also useful in the COVID-19 pandemic where real-life theatre exposure is limited [4]. Animated video can be used alongside with along with recorded live surgical videos to complement simulation training. This would help the trainee to "observe" the whole scenario rather than just the surgical steps. It would also benefit other theatre team members to help familiarisation with necessary steps/adjuncts to deal with the vitreous loss [5].

We echo the authors' emphasis on reshaping training following the COVID-19 pandemic to re-enhance environment surgical training. Effective learning requires carefully planned educational intervention using instructional design frameworks.

Jia Y. Ng (D) ${ }^{1 凶}$, Daniela Vaideanu-Collins ${ }^{2}$ and Susie Schofield ${ }^{3}$ ${ }^{1}$ Sunderland Eye Infirmary, Sunderland, England. ${ }^{2}$ Department of Ophthalmology, James Cook University Hospital, Middlesbrough, UK. ${ }^{3}$ Centre for Medical Education, University of Dundee, Dundee, UK.

凶email: jiang@doctors.org.uk

\section{REFERENCES}

1. Ferrara M, Romano V, Steel DH, Gupta R, lovino C, van Dijk EHC, et al. Reshaping ophthalmology training after COVID-19 pandemic. Eye. 2020; https://doi.org/ 10.1038/s41433-020-1061-3.

2. Merrill MD. First principles of instruction. ETRD. 2002;50:43-59.

3. Peyton JW. Teaching and learning in medical practice. Herts: Manticore Europe Ltd; 1998.

4. Ng JY, Vaideanu-Collins D, Schofield S. Comments on: essentials of setting up a wet lab for ophthalmic surgical training in COVID-19 pandemic. IJO. 2021;69: 1333-5.

5. Lockington D, Belin M, McGhee CNJ. The need for all cataract surgeons to run a regular vitreous loss fire drill. Eye. 2017;31:1120-1.
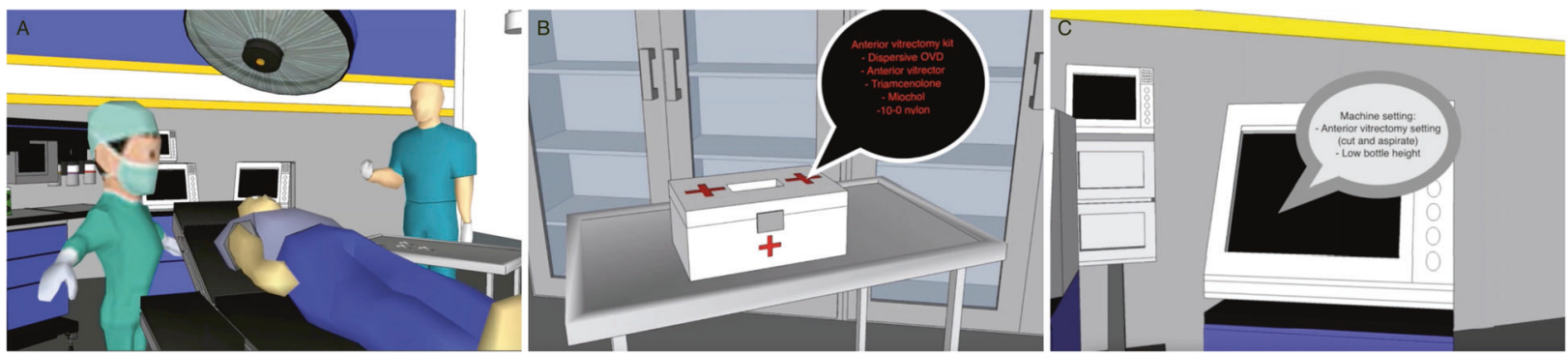

Fig. 1 Animated video demonstrating scenario in the theatre when posterior capsular rupture (PCR) occurs. A Surgical theatre scene created using SketchUp. B Anterior vitrectomy pack consisting essential items needed for anterior vitrectomy. C Recommended settings for anterior vitrectomy demonstrated. 


\section{AUTHOR CONTRIBUTIONS}

JN and DVC designed the study. JN drafted the manuscript. JN, DVC and SC revised and approved the final manuscript. JN, DVC and SC agreed to be accountable for all aspects of the work.

\section{FUNDING INFORMATION}

The authors received no specific funding for this work.

\section{ADDITIONAL INFORMATION}

Correspondence and requests for materials should be addressed to J.Y.N.

Reprints and permission information is available at http://www.nature.com/ reprints

Publisher's note Springer Nature remains neutral with regard to jurisdictional claims in published maps and institutional affiliations.

\section{COMPETING INTERESTS}

The authors declare no competing interests. 